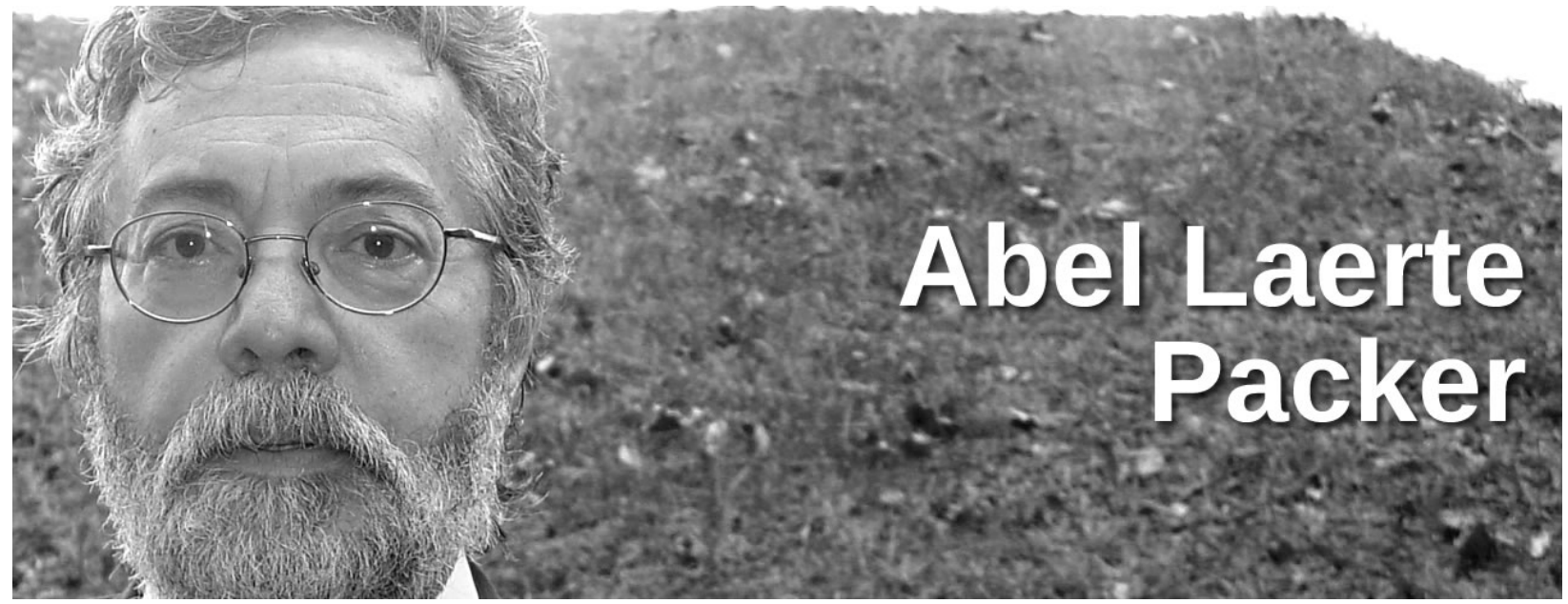

\title{
O princípio do acesso livre é parte da essência de nossa profissão
}

INTERVIEW

\section{Resumo}

Entrevista a Abel Laerte Packer (Brasil). Coordenador do projeto SciELO (Biblioteca Científica Eletrônica em linha) e assessor da Fundação de Amparo à Pesquisa do Estado de São Paulo (FAPESP).Magíster em Bibliotecología pela Universidade de Syracuse, Nova York, foi diretor do Centro Latino-Americano e do Caribe de Informação em Ciências da Saúde (BIREME/PAHO/WHO).

\section{Palavras-chave}

Abel Laerte Packer; Acesso aberto; Periódicos científicos; SciELO; Profissionais; Entrevistas

\section{The principle of open access is an essential part of our profession}

\section{Abstract Title}

Interview with Abel Laerte Packer (Brazil). Project coordinator of SciELO (Scientific Electronic Library Online) and Advisor to the da Fundação de Amparo à Pesquisa do Estado de São Paulo (FAPESP). Master's degree in librarianship by Syracuse University, New York, has been director of the Latin American and Caribbean Center on Health Sciences Information (BIREME/PAHO/WHO).

Keywords Title

Abel Laerte Packer; Open access; Scientific journals; SciELO; Professionals; Interviews 


\section{Qual é sua avaliação do desenvolvimento conseguido pelos periódicos científicos em América Latina?}

Packer: A América Latina e o Caribe tiveram, nas últimas três e/ou quatro décadas, um crescimento notável na sua capacidade de pesquisa científica, com a elaboração de projetos inovadores e produção de artigos indexados internacionalmente às grandes bases, como a Web of Science, MEDLINE e outras.

A partir desse processo, melhoraram, progressivamente e de modo muito significativo, a comunicação por intermédio dos periódicos científicos nacionais e regionais da América Latina. De modo que há um papel muito importante para que a ciência que se produza na América Latina e o Caribe seja disponibilizada nacional e internacionalmente, não somente mediante os chamados periódicos da corrente principal, mas também pelos periódicos publicados nacionalmente e nos idiomas castelhano, português e, também, em inglês. De modo que a perspectiva, a função e o papel da edição científica nacional e dos periódicos científicos nacionais são cruciais para dar suporte e para contribuir para o aperfeiçoamento da investigação científica.

De fato, nos últimos anos a Web of Science ampliou a indexação dos periódicos científicos da América Latina e, hoje, a representatividade é muito grande. Esperamos, com base nos indicadores que possuímos, que esse crescimento continue ocorrendo nos próximos anos. Assim, o futuro dos periódicos científicos da América Latina e o Caribe se mostra bastante promissor, ainda que existam muitos desafios relativos à contínua melhora de sua qualidade.

\section{O projeto SciELO constitui um sucesso como proposta regional regional para a promoção da comunicação científica. Como pode resumir este fato?}

Packer: Tradicionalmente, o problema que se identificou como crônico para o desenvolvimento dos periódicos científicos na América Latina e o Caribe, e que foi identificado como um círculo vicioso, é a dificuldade que tinha (e que de certa forma continua tendo) grande parte dos periódicos científicos em ter presença internacional, em ter alto grau de indexação, ou como dizemos hoje em dia, inserção no fluxo global de informação científica.

Há 13 anos iniciamos o Projeto SciELO (Scientific and Electronic Library Online), que é um projeto liderado pela Fundação de Amparo à Pesquisa do Estado de São Paulo, em colaboração com a BIREME (Centro LatinoAmericano e do Caribe de Informação em Ciências da Saúde), e os conselhos nacionais de ciência e tecnologia e, também, os institutos de pesquisa em universidades da América Latina. SciELO nasce com a estratégia de dar visibilidade e promover a inserção internacional dos periódicos científicos da América Latina e o Caribe, utilizando como estratégia dois pilares:

$\left.1^{\circ}\right)$ a publicação dos periódicos em coleções nacionais controladas por critérios de qualidade internacionais, visando não somente o formato dos periódicos, sua periodicidade e pontualidade, mas principalmente a qualidade da pesquisa que publicam. Então, essas coleções seguem normas de controle de qualidade e, ao longo do tempo, vão melhorando progressivamente;

$2^{\circ}$ ) é o acesso aberto, este entendido como a disponibilidade on-line de texto completo dos periódicos científicos, de forma tal que interage com os índices internacionais, incluindo, por exemplo, Google Scholar, LILACS, Agris da FAO, MEDLINE, PubMed etc. Logo, SciELO, de certa forma, é, na opinião de muitos, o mais importante fenômeno ou importante programa de comunicação científica, não apenas da América Latina e o Caribe, mas de todo o mundo em desenvolvimento.

E de fato, SciELO contribuiu para melhorar significativamente a qualidade da publicação dos periódicos científicos, assim como a indexação internacional. Atualmente, estimamos que o conjunto da rede (SciELO) tenha mais de 17 milhões de downloads de artigos por mês, o que é uma operação gigantesca.

Hoje, SciELO é acessível de todas as partes do mundo, e de fato há uma distribuição em que predomina o acesso desde a América Latina e, após, Portugal e Espanha; mas existe também acesso internacional. SciELO é conhecido hoje em dia e é referência internacional na área de acesso aberto utilizando o que se chama a via dourada, onde se publica o periódico completo on-line. 
Então, América Latina se apresenta hoje em dia em uma posição muito superior a outras regiões em desenvolvimento, como é o caso da África e da Ásia e, também, de alguns países do mundo desenvolvido que têm problemas de publicações em diferentes idiomas. A contribuição de SciELO, já evidenciada por indicadores, por números, estatísticas, foi conseguir maximizar a visibilidade nacional, regional e internacional de nossos periódicos científicos.

\section{Qual foi o papel dos profissionais da informação, os bibliotecários, neste projeto?}

Packer: A experiência de SciELO, já com 13 anos, têm sido muito interessante na área da Ciência da Informação em geral. Sua estratégia faz com que SciELO, o programa, o espaço, tudo, represente uma convergência de todos os atores da comunicação científica, pelo fato de termos os autores, os editores, os indexadores e os bibliotecários. Particularmente, eu gostaria de destacar, porque eu também sou um bibliotecário, o papel que os bibliotecários cumprem no desenvolvimento e na manutenção de SciELO. São os bibliotecários que têm as condições, a formação, para fazer esse trabalho de intermediação e dotar o espaço de publicação de SciELO com a obediência às normas, com o seguimento de desempenho e de preservação. São esses princípios da função de Biblioteconomia que SciELO tem incorporado e representa um de seus fatores mais importantes de êxito. Então, tanto os autores como os editores contam no desenvolvimento de SciELO com toda uma rede de bibliotecários que contribui para o processo de controle de qualidade, para o processo de seleção, para o processo de marcação de textos e de seguimento. De forma que, SciELO representa, como espaço de convergência, o que chamamos de produtores, intermediários e usuários da informação científica, entre os quais eu queria novamente destacar o papel dos bibliotecários.

\section{Muitos profissionais da informação na região apreciam seu trabalho nestas iniciativas. Que mensagem compartilharia com eles?}

Packer: Aproveito também a oportunidade para enviar saudações para toda a comunidade de bibliotecários e profissionais de informação da América Latina e Caribe, e reforçar que a função que exercemos é crítica e é fundamental para a democratização do acesso e da publicação do conhecimento de que faz parte hoje como uma função essencial da sociedade da informação, da sociedade do conhecimento. Assim que, orgulhem-se da profissão que têm e enfrentamos sempre, com certeza, o desafio de atualizar-nos, de adotarmos novas metodologias e tecnologias, mas em que o princípio da biblioteca pública, o princípio do acesso livre, do acesso aberto ao conhecimento científico, são partes da essência de nossa profissão.

\section{Produção}

Tradução: Cristina da Cruz de Oliveira

Transcrição: Rafael Guimarães Botelho

Edição: Julio Santillán-Aldana

Agradecimento: Universidad Peruana Cayetano Heredia (UPCH).

\section{(cc) BY-NC-ND}

This work is licensed under a Creative Commons Attribution-Noncommercial-No Derivative Works 3.0 United States License.

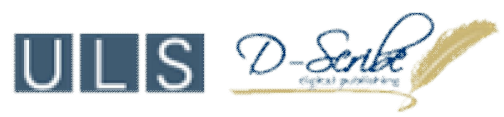

This journal is published by the University Library System of the University of Pittsburgh as part of its D-Scribe Digital Publishing Program and is cosponsored by the University of Pittsburgh Press. 